Para enlazar con este artículo / To link to this article:

https://doi.org/10.6035/MonTI.2020.12.04

Para citar este artículo / To cite this article:

Bosch-Baliarda, Marta; Olga Soler-Vilageliu \& Pilar Orero. (2020) "Sign language interpreting on TV: a reception study of visual screen exploration in deaf signing users." In: Richart-Marset, Mabel \& Francesca Calamita (eds.) 2020. Traducción y Accesibilidad en los medios de comunicación: de la teoría a la práctica / Translation and Media Accessibility: from Theory to Practice. MonTI 12, pp. 108-143.

\title{
SIGN LANGUAGE INTERPRETING ON TV: A RECEPTION STUDY OF VISUAL SCREEN EXPLORATION IN DEAF SIGNING USERS ${ }^{1}$
}

\author{
MARTA BOSCH-BALIARDA ${ }^{2}$ \\ Marta.Bosc@uab.cat \\ Universitat Autònoma de Barcelona \\ Olga SOlER-VILAGELIU \\ Olga.Soler@uab.cat \\ Universitat Autònoma de Barcelona \\ PILAR ORERO \\ Pilar.Orero@uab.cat \\ Universitat Autònoma de Barcelona
}

1. Acknowledgments: We gratefully acknowledge: Vanessa Beroy, Noelia Hernández and Sílvia Pujol for the translation and adaptation of the signed versions; RTVE, the Spanish Radio and Television Corporation, and WEBVISUAL TV for video production; Juan Pedro López-Velasco and Carlos Alberto Martín-Edo for video post-production and developing the technical implementation and delivery system for the questionnaire; Idoia Vallverdú-Segura for the graphic design of figures $1-4$ and 7; FESOCA, the National Association of the Deaf in Catalonia, and CNLSE, the Centre for Language Normalization of Spanish Sign Language, for their collaboration and support.

2. All authors are TransMedia Catalonia members (2017SGR113, 2017). This research has been conducted in the Department of Translation and Interpretation in the Autonomous University of Barcelona (UAB) within the PhD program in Translation and Intercultural Studies. This research has been partially funded by the $\mathrm{H} 2020$ projects ImAc grant no. 761974 and EasyTV grant no. 761999. 


\begin{abstract}
We studied how sign language users responded to a screen composition including a larger screen for the content and a smaller screen for the sign language interpreter. 32 deaf users participated in this experiment, watching four similar clips with four different screen compositions. We registered the pattern of screen exploration with Eye Tracker, and we assessed content recall with two questionnaires. Our results show that sign language users mainly look at the sign language interpreter screen. Participants tend to look more often and for longer time at the SLI side closer to the main screen. Results are interpreted in terms of perceptual strategies developed by Sign Language users.
\end{abstract}

Keywords: Sign language interpreting; Accessibility for the deaf; Access in HBBTV; Service quality; Eye-tracking.

\title{
Resum
}

Hem estudiat com els usuaris de llengua de signes (LS) exploren una composició de pantalla formada per una pantalla gran per al contingut i una de petita per a l'ILS. 32 usuaris sords han vist quatre clips similars amb quatre composicions de pantalla diferents. Hem registrat l'exploració de pantalla amb Eye Tracker i avaluat el record amb dos qüestionaris. Els resultats mostren que els usuaris miren principalment la pantalla de l'ILS i tendeixen a mirar més sovint i més estona el costat de l'ILS més proper a la pantalla principal. Els resultats s'interpreten en termes d'estratègies perceptives desenvolupades pels usuaris de LS.

Keywords: Interpretació en llengua de signes; Accessibilitat per a sords; Accessibilitat en la televisió connectada; Qualitat dels serveis; Moviments oculars.

\section{Towards the accessibility of sign language in media platforms}

Sign language interpretation (SLI) made its appearance on TV around 1950 (Ladd 2007) and is thus considered one of three mature TV accessibility services along with subtitling and audio description (European Commission 2010; European Parliament 2010; European Parliament 2015; Looms 2009). There are also some newer, hybrid accessibility services, such as audio subtitling, and easy to read subtitles or audio description, often offered with personalisation options (Bernabé \& Orero forthcoming). Some more recent accessibility services to arise include clean audio and the numerous possibilities offered through personalisation options (Mas \& Orero 2018). Technology 
and end user lobbying are the two forces behind the development and mainstreaming of accessibility services.

The latest technological advances have contributed to an increase in informative, social and cultural content, transmitted through various media platforms. The new TV formats (Digital TV —DTV_ and more recently Hybrid-Broadcast-Broadband - HbbTV or Smart TV) are mixed formats that combine TV broadcasting with Internet broadband access. These more recent formats allow the customisation of content and in particular, open up new possibilities to deploy personalised, synchronised access services, which are crucial to grant accessibility to information broadcasting (Martín, Orero, Menéndez \& Cisneros 2015). Validating the optimal parameters for any personalised access service implementation is key to ensure best practice in future commercial use and to provide guidance to broadcasters deploying the services. However, as for SLI it is still unclear which formal parameters are to be implemented to fully explore the possibilities of its customization, that grant quality sign language access services and equal rights in media accessibility for sign language users.

The provision of accessible audiovisual media services in Europe is covered by the European Audiovisual Media Services Directive. Article 46 of the directive states that access to audiovisual media forms part of the "right of persons with a disability and of the elderly to participate and be integrated in the social and cultural life of the Union" and specifies that "the means to achieve accessibility should include, but need not be limited to, sign language, subtitling [and] audio-description." Also according to article 7 of the Audio Visual Media Standard Definition (AVMSD), "Member States shall encourage media service providers under their jurisdiction to ensure that their services are gradually made accessible to people with a visual or hearing disability." It is then up to each member state to gradually make appropriate services available, with a view to reaching targets of $100 \%$ for subtitling of public-service broadcasting, and $10 \%$ for both audio description and sign language.

\subsection{Sign language interpreting on television}

Stakeholders have devoted many efforts towards attaining information access (Orero et al. 2014). Deaf and hard-of-hearing people are active advocates of 
their language and cultural rights. Pursuing this goal and promoting development and improvement of services to access audio-visual content — namely, subtitling and sign language services. Traditionally, broadcasters preferred subtitling over sign language, arguing that it was more cost effective and that it allowed them to reach the entire target group of deaf and hearing-impaired persons (Grbić 2002 as cited in Kurz \& Mikulasek 2004: 83). However, sign language communities strove (and are still striving) for their language rights; to grant full accessibility and the provision of access to media in sign language too. In Europe, a present example of this long advocating tradition can be found in the ongoing European Disability Strategy Survey organised by the European Union of the Deaf to gather information from different deaf associations within the EU (EUD 2019). The survey tackles specific questions on the provision of sign language in public websites, public TV channels and TV programmes. The goal is to create a document for the European Commission detailing the real implementation of the strategy for deaf people as is actually experienced by deaf communities across the EU.

There are different ways to include sign language in TV programmes: sign-presented programmes, or programmes showing deaf sign language users as presenters, contributors or characters; and sign-interpreted or sign-translated broadcasts, as two ways to make the content of speech or other sounds in the programmes available to sign language users (National Disability Authority 2014). Traditionally, media sign interpreters have been native and non-native hearing professionals, however deaf translators/interpreters have been provisioned too, providing a better cultural match with the target audience (Allshop \& Kyle 2008; De Meulder \& Heyerick 2013; Duncan 1997; Stone 2007; Stone \& West 2012). Most broadcasters provide access through sign language interpreting services on screen (CNLSE 2015: 15; NDCS, 2005: 5). Even though SLI made its first appearance on TV nearly 70 years ago, it is still an underdeveloped and under-researched access service.

The report from the European Broadcasting Union (EBU, 2016) and the report from the European Regulators Group for Audiovisual Media Services (ERGA, 2016) point towards the need to improve the current standard of the service. On average, public broadcasters deliver sign language in $4 \%$ of programmes, mostly daily news (EBU 2016: 40-41). When an accessibility service has a limited number of broadcast hours, as is the case with sign 
language services, it is important to prioritise the genre of the programme since it has social implications and secures the full participation of citizens in society and the fulfilment of equal rights (Geerts, Cesar $\&$ Bulterman 2008; Mäkipää \& Hämesalo 1993: 9; NDCS 2005; Seleskovitch 1997: 562; Steiner 1998). The Council of Europe recommends that "information on daily politics, state developments and news should be made available to sign language users. This should be secured by in-vision sign language interpreters and subtitling in television; and/or by creating broadcasting formats/media (on TV or the Internet) made by sign language users in sign language(s)" (Krausneker 2008: 35).

Furthermore, not all broadcasters observe the compliance norms determined by the governments. Public broadcasters are obliged to offer their services to all citizens yet SLI is still not a mainstreamed accessibility service for broadcasters when compared to subtitling (Kurz \& Mikulasek 2004). For example, in Spain the General Law on Audio-visual Communication (Spanish Parliament 2010) determines that Spanish public TV broadcasters must offer at least 10 hours/week of sign language, and commercial broadcasters must offer at least 2 hours/week. Although the number of hours, and number of broadcasters offering sign language access services has grown since the law was passed, the minimum of sign language broadcast hours have not yet been reached (CNLSE 2015; CNLSE 2017: 6; Utray \& Gil Sabroso 2014). Therefore, the targets concerning the quantity of SLI access services on TV have not yet been met, but more crucially the quality of accessible content in sign language in terms of on-screen representation has not been met either.

\subsection{Sign language interpreter on-screen format}

In addition to the limited broadcast time and variety of TV genres offered in sign language, best practise guidance based on test results for this access service is also limited. Although some guidelines for broadcasters are available, (CNLSE 2017; Independent Television Commission 2010; National Disability Authority 2014; Ofcom 2007) they are somewhat tentative and sometimes created from parallel issues that have been recognised for other content access services rather than research on sign language on TV (National Disability Authority 2014). Nonetheless, the service user perspective on quality criteria 
has gradually been introduced with results coming from both focus groups and surveys with deaf audiences (Bosch-Baliarda, Orero \& Soler-Vilageliu forthcoming; DTV4ALL 2008; Gil Sabroso \& Utray 2016; HBB4ALL 2017; Kyle 2007; Steiner 1998; Xiao \& Li 2013). In this respect, there are still central questions to be answered in order to find quality criteria, which will establish a good standard definition of SLI and offer an optimal service to the signing audiences. Which parameters are chosen by different broadcasters to deploy the SLI service? How can we define them? And, which are the best to deploy an optimal service?

In a survey carried out at our university, Redón (2014) found remarkable differences between 100 different broadcasters all over the world regarding size, shape and position on screen of the sign language interpreter. SolerVilageliu, Bosch-Baliarda \& Orero (2015) identified within this sample several format parameters that differed among broadcasters: type of on-screen insertion (picture-in-picture / half screen (split screen) / Chroma key); shot size (long shot / medium long shot / mid shot / medium close-up; interpreter's clothing colour (plain light colour / plain dark colour / patterned or multicoloured); size of the interpreter's screen (small / medium / large); on-screen positioning of the interpreter (right / left, top / centre / bottom); position of the interpreter (standing / seated).

Subsequently, these authors surveyed two focus groups in order to find out which parameters were relevant for the consumers of TV sign language interpreting (Bosch-Baliarda, Orero, Soler-Vilageliu forthcoming). The participants were deaf sign language users that belonged to various Catalan Deaf Associations. All participants felt that sign language access services on Catalan/Spanish TV did not meet quality standards, as they understood them, in order to guarantee accessibility. It was their belief that Spanish broadcasters simply included sign language in their programmes in order to comply with regulations but had no interest in providing accessibility to sign language users.

This survey clarified the relevance of some parameters, while others were considered irrelevant in terms of usability and quality of the SLI access service. For example, users considered gender, age, appearance and position of the interpreter to be of least importance. Whereas speed, size and colour combinations were the parameters that had a greater impact on screen legibility. 
In order to guarantee a good contrast with the background, most participants considered embedding the interpreter in a sub-screen with borderlines to be better than chroma keying. Using this technique, the background colour can be set to contrast with clothing and skin colour so that all three-dimensional language details can be perceived accurately, prevent eye-fatigue and enhance legibility.

All participants considered that the most important on-screen parameter to grant accessibility was the size of the interpreter's window. Most of them agreed that taking roughly a third of the split screen and using a medium shot or a medium-large shot would be ideal for news broadcasts. However, they acknowledged that it would not be appropriate for other television programmes, such as interviews, films or documentaries where a larger scene screen was preferred.

There was no agreement among the participants regarding the on-screen position of the interpreter: some participants indicated that they did not consider it to be an important parameter, some preferred left positioning over right. This result contrasted with previous findings in which users reported to prefer the interpreter to be located on the right side of the screen (DTV4all, 2008; Gil Sabroso \& Utray, 2016). These contrasting results could be due to frequency of exposure or the viewers' habits. According to Gil Sabroso and Utray, Spanish TV on-screen presentation is in the bottom right position in $90 \%$ of programmes, whereas the Catalan public broadcaster inserts the SLI screen in a left position for its daily news programme. Catalan signers could therefore be accustomed to reading the split screen including the SLI in both on-screen positions. This result raised the question of whether on-screen position user preferences were influenced by culture and consumption habits or by more general, visual attentional behaviours. This information was used to set up our experiment, which we describe in section 2. Before that, we report briefly on previous research into eye movements and visual attention in sign-language users.

\subsection{Information processing in sign language perception}

Watching TV with a split screen for SLI is a demanding task requiring skilled, divided attention, that is, distributing attention between the two simultaneous 
stimuli (Nebel et al. 2005: 760). Visual attention not only needs to be distributed between the two composites of the split screen, but also within the SLI screen. Sign languages embody a complex, visual language input using different body parts as active articulators to convey meaning, namely the hands, facial features, the head and movable upper body parts (Sandler 2013). The existence of two identical, active articulators is a unique characteristic of the sign language modality. However, the hands exhibit different articulatory behaviours and do not tend to act independently. One hand is the dominant hand and is used as the manual, active articulator in one-handed signs an in two-handed signs in which only one hand moves. The dominant hand is generally the preferred hand of the signer. The other hand, commonly referred to as the non-dominant hand, may concur in the signal with different linguistic domains (Sandler 2013). When used as a phonological unit in two-handed signs, the non-dominant hand is either redundant or largely restricted in the hand-shapes and movements it can exhibit (Battison 1978). Therefore, the most visually salient articulators attracting visual attention would be the face and the dominant hand.

As Siple (1978) noted in her seminal paper 'Visual constraints for Sign Language Communication', sign language users tend to fixate on the face of their interlocutor. Although the hands carry the main lexical information in sign language, the face conveys very important cues to the meaning of signed utterances (Siple 1978: 96). Thus, according to Siple, signers look at the face during their communication and follow hand movements with peripheral vision. Later research in the literature was consistent with Siple's previous reports. Bavelier's (2001) research supported the idea that deaf individuals rely more heavily on monitoring peripheral, visual space to detect new information in their environment. Her results showed that deaf individuals displayed a bias towards better performance in the peripheral field than the central field, whereas hearing controls and hearing signers displayed the opposite bias (Bavelier et al. 2001: 8934).

Another visual processing feature that constitutes a specific, visual exploration pattern for the deaf is found in the lateralisation of motion processing. Bavelier et al.'s (2001) research showed left-hemisphere enhancement in the deaf. Behavioural studies of motion processing indicated that deaf individuals performed better in the right visual field (left hemisphere) than the left visual 
field (right hemisphere), whereas hearing individuals showed the opposite pattern (Bavelier et al. 2001: 8937).

More recent papers using eye-tracking devices also confirm Siple's observations. Agrafiotis, Canagarajah, Bull \& Dye (2003) studied the eye movements of 11 British Sign Language users while watching four short narratives. Their goal was to optimise the signal coding of the interpreter's recording by reducing the bit rate needed to transmit the video signal. They found that users consistently focused their attention on the face and mouth of the interpreter and did not focus on their hands. This finding helped them to adopt a foveated approach to sign language video coding that prioritises the quality of the important areas (the interpreter's head and mouth) and diminishes the bit rate of the surrounding areas. Left-hemisphere superiority was also reported for peripherally presented stimuli (Parasnis \& Samar 1985).

The finding of Agrafiotis et al. (2003) has been replicated by some other studies. Letourneau \& Mitchell (2011) compared the ocular fixations of hearing people and deaf people, who tried to identify identity and emotions on expressive faces. They were presented complete faces as well as upper halves and lower halves of faces. These authors found that hearing people devoted more attention to the upper halves in order to identify identity and emotion, but deaf people devoted an equal amount of attention to the upper and lower halves of the faces. Therefore, they concluded that deaf people develop a specific visual exploration pattern.

This finding has been replicated in a recent study by Dye, Seymour and Hauser (2016), who pointed out that sign language users' attention shifts to the lower part of a visual scene. In their paper, the authors re-analysed the data from a former experiment (Dye et al. 2009). Dye et al. (2009) found evidence that both deaf adults and children (7-10 years of age) direct their visual attention to the periphery of the visual field. The new data analysis of 2016 suggests that users of a visual-gestural language (both deaf and hearing), favour a redistribution of visual attention to the inferior half of the visual field. The authors claim that this redistribution of visual attention is an adaptation that allows signers to focus their attention to the face in order to gather important information about meaning and intention of the utterances while, simultaneously following the information conveyed by the signing hands with peripheral vision. 
However, these studies did not address the specifics of signing individuals watching contents with a split screen. Wehrmeyer's research (2014) pioneers the use of eye tracking metrics. Her study describes the viewing patterns of deaf and hearing users whilst they watch news broadcasts in a split screen showing both sign language, in a right position, and subtitles, in a central bottom position. As a main finding, her data indicates that deaf sign language participants focus their attention primarily on the interpreter and secondly on the imagery footage, but that they do not use subtitles or lip-reading to access the news contents.

\subsection{Study overview}

The goal of this present research is to contribute towards establishing quality criteria to help advance the deployment of SLI access services on TV in terms of perception and usability. The study explores whether or not there is an on-screen format, regarding size and position of the SLI split screen, that can enhance screen legibility and content comprehension, or one that is preferred or perceived as optimal by the users. To study this particular situation in sign language, users could contribute to bettering the development of sign language services offered by broadcasters.

This experiment is part of the sign language pilot tests developed within the European project Hybrid Broadcast Broadband for All (HBB4ALL) on media accessibility. Our experiment was designed to parallel the pilots with user tests on subtitling within the project (HBB4ALL 2017; Oliver Moreno 2017). In our experiment we wanted to explore whether watching SLI in different, split screen configurations has any effect on information access.

In the experiment the signing users watched four different parts of a documentary film that were edited using four controlled formats of split screen configuration. The different formats varied on two counts regarding size and position of the SLI sub-screen as independent variables: two sub-screen sizes (Small: 1/5 of the screen width; Medium: 1/4 of the screen) and two positions (right/left). See Figures 1 - 4 below.

In addition, we recorded participants' eye movements in order to collect data from deaf signing users' behavioural patterns regarding attention distribution, perception and information processing of stimuli on a split screen 
displaying two types of information on each screen: (1) The sign language interpreted, textual content on a sub-screen, and (2) the documentary scene with non-verbal content on the main screen. After each clip, participants responded to three sets of questions on visual, verbal memory (language recall), visual, non-verbal memory (scene recall) and user preferences. The scope of this present article focuses on the results from the eye tracking measures and the recall tests only.

With these questionnaires we wanted to test user comprehension and recall of language content and visual information from the clips, and check if screen configuration had any effect on them. Is there any difference regarding visual exploration and attention allocation on the screen in the four different conditions? Do differences in attention allocation affect visual recall results (both language and scene)? Do SLI size and/or position affect how users read the on-screen sign language or comprehension and recall tasks? Are user preferences affected by visual exploration behaviours?

Regarding eye tracking measures, we want to investigate if there are any differences in visual behavioural patterns (number and duration of fixations and visits), and in turn, between the four format conditions (size and positions). We predict that there is a difference in the eye tracking metrics between the two parts of the split screen, SLI and Content screen. As previously found in Wehrmeyer (2014), we predict that deaf users will focus their attention primarily on the interpreter. Thus, the number and duration of fixations and visits will be higher on the SLI screen than on the documentary scene screen. As for the format conditions, we do not expect to find significant differences in eye tracking metrics between the four formats; in this respect our study is exploratory.

Although previous literature shows that attention is focused on the face and meaningful information is accessed from the hands through peripheral vision (Dye et al. 2009), we want to explore whether the visual, attentional patterns within the SLI area differ in the right and left position conditions. Left and right positions do not differ in the relative distance between the scene and the face, as a source of linguistic information. However, when a righthanded interpreter is displayed on the right side of the screen, their dominant hand (the right hand) is more proximal to the scene screen whereas the left hand is more proximal in the left conditions. We hypothesise that this will 
have an effect on the distribution of visual attention between the dominant and non-dominant sides of the SLI. If the professional interpreter is righthanded, we hypothesise that the number and duration of fixations and visits will be higher on the ipsilateral SLI area, the side of the body including the dominant hand (or $\mathrm{H1}$ ).

Regarding the information recall measures, we want to explore if the recall tests produce different scores, according to the different conditions. We hypothesise that the size of the stimuli will produce differences. Our study is exploratory on this matter.

As for the on-screen position, we hypothesise that there will be a difference in recall scores between right and left positions. We predict that our participants will obtain higher visual recall scores when the scene screen is located in the right visual field. This would be consistent with the reported enhanced performance during motion visual tasks in the right visual field, left-hemisphere bias (Bavelier et al. 2001).

\section{The experimental reception study}

\subsection{Method}

\subsubsection{Participants}

Participants in this study were 32 deaf sign language users ( $16 \mathrm{men} / 16$ women) from the metropolitan area of Barcelona. Their ages ranged from 17 to 76 years (mean 40, STDEV 15). All of them reported using Catalan Sign Language (Llengua de signes catalana, LSC) to communicate in everyday life. They were recruited through the mailing list and social media of the National Association of the Deaf (Federació Catalana de Persones Sordes, FESOCA) via a written and signed video message with the help of deaf research facilitators. Two users were removed from the experiment due to technical malfunctioning.

\subsubsection{Material}

\subsubsection{Apparatus}

An eye tracker, a Tobii T60 integrated into a 17 -inch monitor run by a Toshiba Portable personal computer was used to display the stimuli and record the participants' eye movements while watching the four picture-in-picture sign 
language video clips. The Tobii T60 screen has a resolution of $1280 x 1024$. It has a sampling rate of $60 \mathrm{~Hz}$. The Tobii Pro Studio software for screen-based eye trackers was used to prepare, administer and record the experiment and for calculating eye tracking metrics and statistics. For statistical analysis and data preparation we used SPSS.

In the analysis, two areas were taken into account in the eye tracking (ET) metrics for the full duration of the clips: the area of interest (AOI) was drawn on the full SLI rectangle area and the remainder of the screen was considered scene (Not AOI). The SLI screen AOI was further divided into symmetrical areas on a vertical axis, either side of the interpreter: namely the ipsilateral side of the torso for the dominant side ( $\mathrm{H1})$ and the contralateral side of the torso for the non-dominant side $(\mathrm{H} 2)$.

Additionally, a MacBook Air personal computer was used to administer and record the cross-modal, bilingual questionnaires.

\subsubsection{Stimuli}

Four clips were extracted from the English documentary film "Joining the Dots" by Pablo Romero Fresco (2012). The rationale behind this choice was that all selected clips would have a similar format, the same subject, and the same characters. Each video clip lasted between 2 and 3 minutes (see Table 1 ). The clips were selected on the basis of meaningful content in the scene. The translation/adaptation of the language content into LSC was carried out by a small team which comprised three members: a deaf native signer and two hearing, non-native, qualified signers. The Spanish subtitles created for the subtitling pilot were used as the source text for the translation/adaptation into LSC to allow full access to all team members (See Oliver Moreno (2017: 55) for a full description of the settings and design parameters for the source subtitles).

The translation procedures included two translations made by the hearing members which were later reviewed by the deaf consultant, who fine-tuned them and indicated which clips should be further adapted. The final edit was approved by all three members. The signing model for the translated documentary clips was a professional hearing interpreter, and a hearing signer, to parallel the most common use signed content on TV. The sign language clips were filmed following professional studio standards by the partner project 
organisation RTVE (Corporación de Radio y Televisión Española, the Spanish public broadcaster). The signed version of the clips was recorded over the voiced version of the subtitles to control the signing pace and later help with synchronisation in post-production.

\begin{tabular}{|c|c|c|c|c|c|c|}
\hline Clips & $\begin{array}{c}\text { Start and end } \\
\text { times }\end{array}$ & Duration & $\begin{array}{c}\text { Number } \\
\text { of words }\end{array}$ & $\begin{array}{c}\text { Number } \\
\text { of } \\
\text { subtitles }\end{array}$ & $\begin{array}{c}\text { Words } \\
\text { per } \\
\text { subtitle }\end{array}$ & $\begin{array}{c}\text { Words } \\
\text { per } \\
\text { second }\end{array}$ \\
\hline clip 1 & 00:00 - 03:10 & 03' 08" (188') & 297 & 47 & 6,31 & 1,58 \\
\hline clip 2 & $03: 10-05: 50$ & 02' 40" (160") & 328 & 46 & 7,13 & 2,05 \\
\hline clip 3 & $05: 50-08: 50$ & 03' 00" (180") & 289 & 45 & 6,42 & 1,61 \\
\hline clip 4 & 08:50 - 11:10 & 02' 20" (140") & 227 & 36 & 6,31 & 1,62 \\
\hline
\end{tabular}

Table 1. Stimuli clips design from the documentary "Joining the dots"

The UPM partner team edited the clips and synchronised the sign language interpretation clip with the documentary scene clip. Later they generated the 16 different clip stimuli combining the four split screen configuration formats (see Figures 1 - 4) for the four video clips.

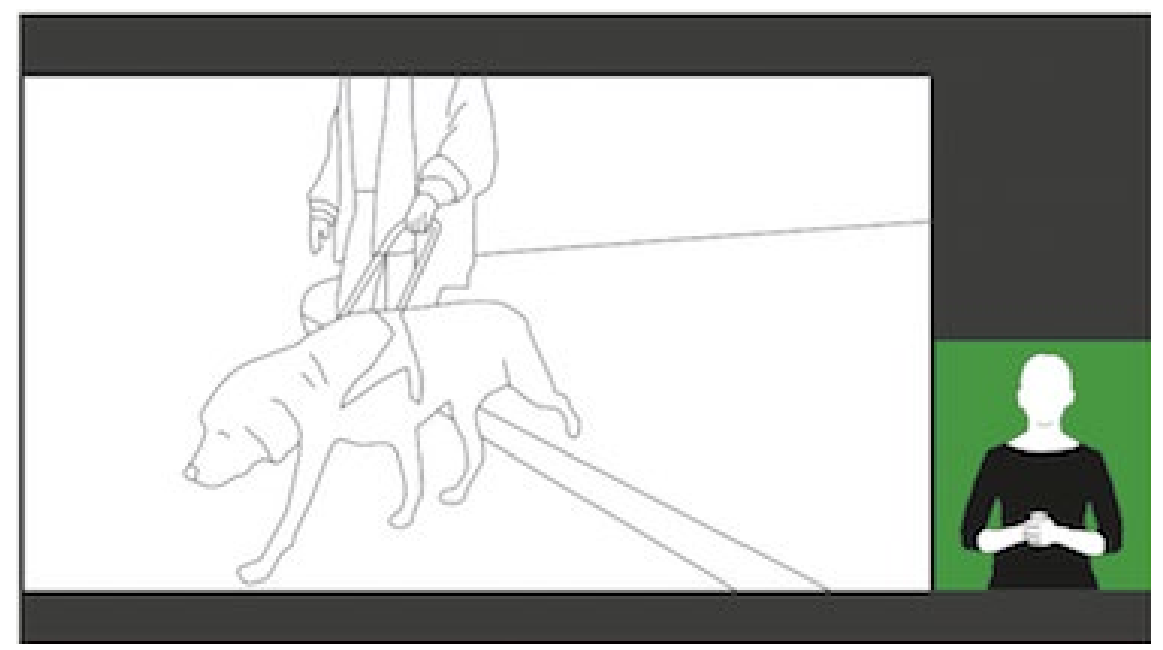

Figure 1. Illustration of the split screen configuration small size ( $1 / 5$ of width screen) and right position of SLI screen (format 1 ) 


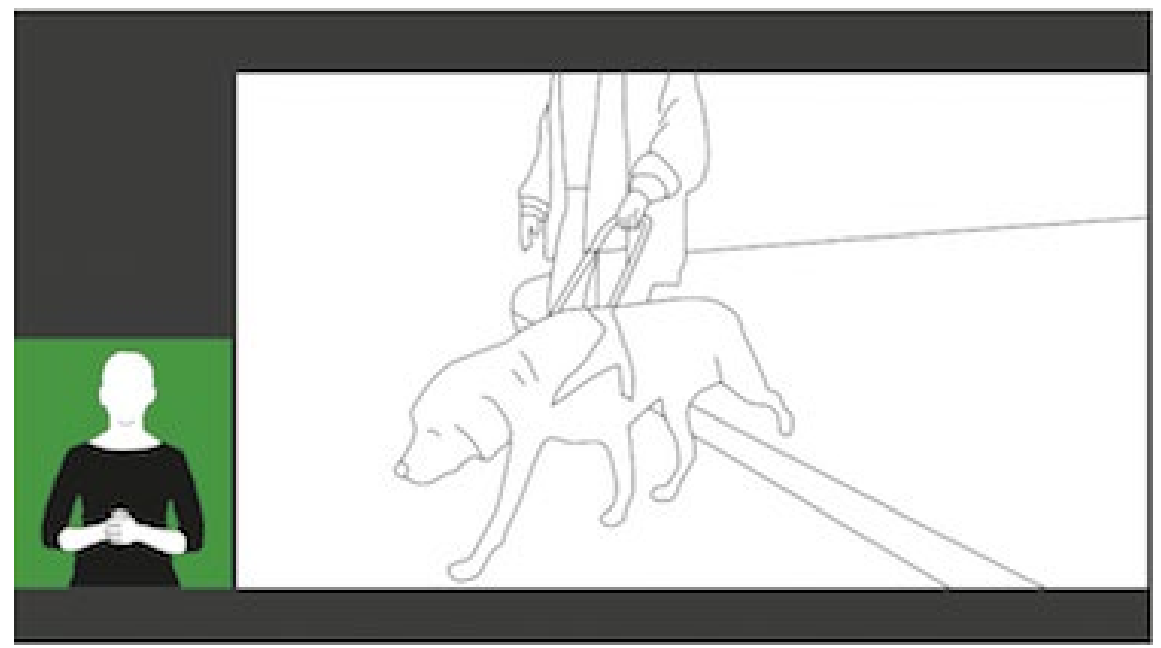

Figure 2. Illustration of the split screen configuration small size ( $1 / 5$ of width screen) and left position of SLI screen (format 2)

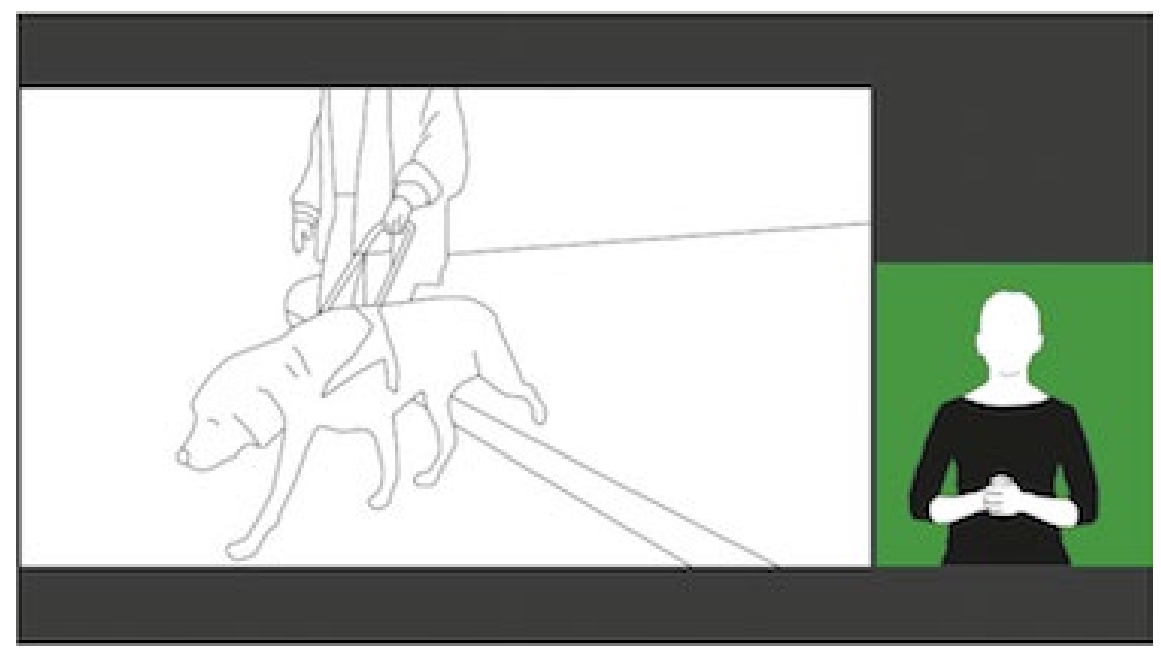

Figure 3. Illustration of the split screen configuration medium size (1/4 of width screen) and right position of SLI screen (format 3) 


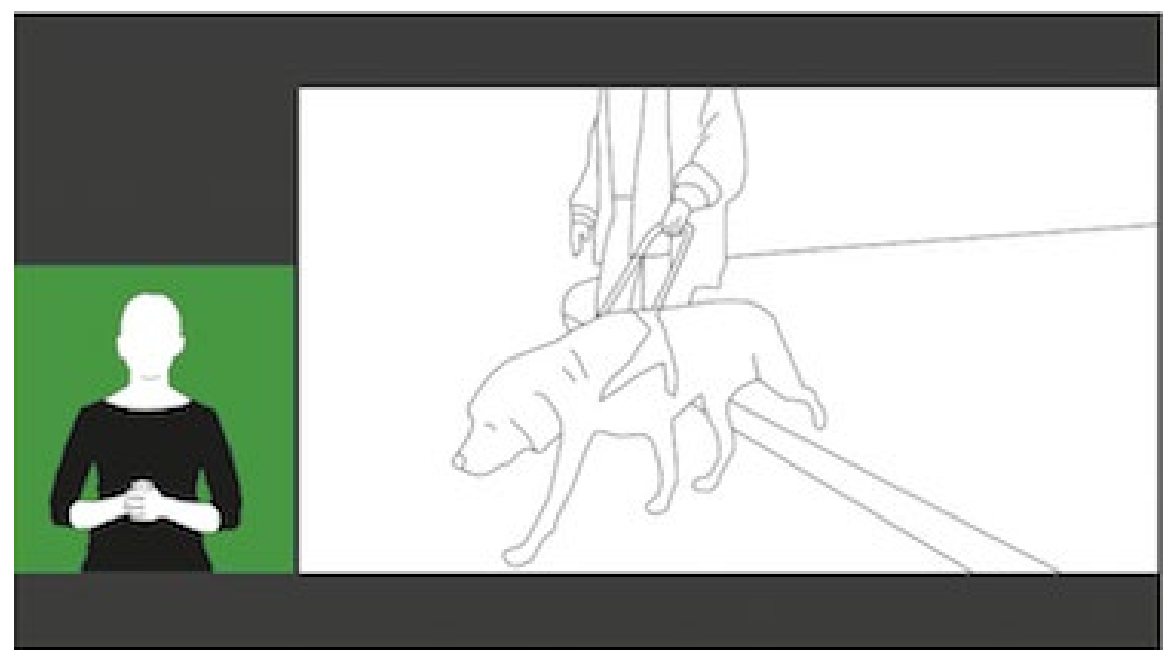

Figure 4. Illustration of the split screen configuration medium size ( $1 / 4$ of width screen) and left position of SLI screen (format 4)

\subsubsection{Other}

Informed consent forms and image release forms were available in video format in LSC signed by a deaf, native signer to grant accessibility and in writing (Catalan and Spanish versions available) to be signed by the participant.

Four cross-modal, bilingual questionnaires (LSC / written Spanish) were designed to be administered by the interviewer, using an innovative webbased application developed in collaboration with the UPM partner team (see Figure 5). This data collection tool was innovative because it used sign language as the main language for accessing, understanding and evaluating the information. The cross-modal, bilingual questionnaire was designed to avoid subordination of sign language with respect to the written language so that the same social and linguistic statuses were given to both modalities in the experiment materials. Additionally, this design enhanced validity and reliability of the results because it didn't require the participants to sight-translate the questionnaires in situ. It also gave a much more accurate and consistent variety of language use between participants and throughout the experiment, thus making it possible to obtain more reliable results. 


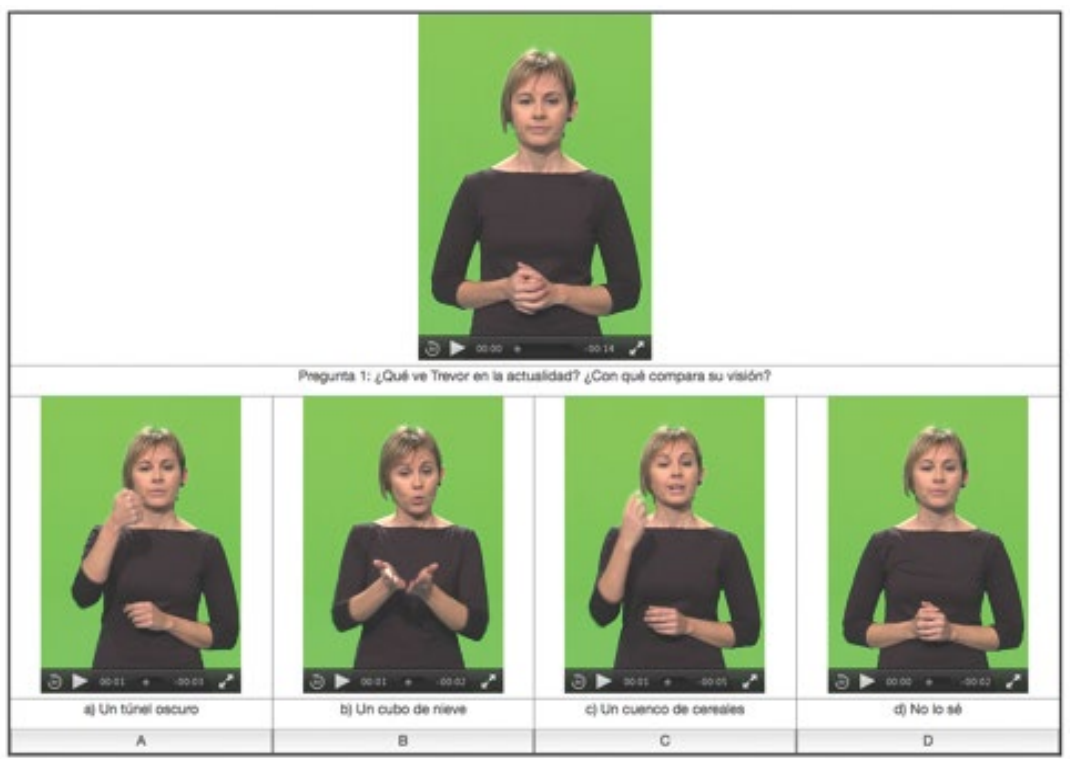

Figure 5. Screenshot of a multiple-choice question from the web-based, cross-modal, bilingual questionnaire.

The four questionnaires included: (1) the demographic data questionnaire, including basic personal information, and data on language skills and TV access service uses; (2) the sign language recall test (visual verbal memory), including five questions on sign language content comprehension and recall for each of the clips; (3) the scene/pictorial recall test (visual non-verbal memory), including five questions on the content recall of the documentary film imagery scene for each of the clips; and (4) user preference test, including questions about the usability and user experience of each of the conditions. The contents of the questionnaires were adapted from the subtitling pilot tests within the project (HBB4ALL 2017; Oliver Moreno 2017). The translation/adaptation approach for the questionnaire items was a mixed approach similar to the one described for the stimuli. However, the signing model for the LSC was the deaf member of the translation team in order to provide a better cultural and language concordance with the target language users. For a more detailed description of the questionnaire design and the 
translation and adaptation approach of the survey items, see Bosch-Baliarda, Soler-Vilageliu \& Orero (2019).

\subsubsection{Design}

In this intra-subject study, each participant was shown four video clips from a set of sixteen. The four clips were presented in the four conditions. The order of presentation was varied randomly for the different participants, following a latin-square design. After watching each clip, the participant was asked to fill out three questionnaires: two on the clip information contents -one on the clip scene contents for visual non-verbal recall; and another for the sign-interpreted, textual contents for visual verbal recall— and one for users' preferences. The eye movements of the participants were recorded for the duration of the documentary clips in the different conditions.

The tested independent variables and conditions were:

- Screen area: SLI versus Main Screen

- Size of the SLI AOI ( small = $1 / 4$ of the total screen width; medium = $1 / 5$ of the total screen width)

- Position of the SLI AOI (right; left)

- SLI screen format combination (format 1: small/right; format 2: small/ left; format 3: medium/right; format 4: medium/left)

- Split SLI screen side: H1, H2

- The dependent variables used were:

- ET measures within the SLI AOI (number of fixations, number of visits; mean duration of fixations, mean duration of visits)

- Visual recall measures (score on language recall; score on scene recall)

\subsubsection{Procedure}

Users were individually tested in different local deaf association offices. In every interview room there was a table and two chairs (one for the interviewer and one for the interviewee). The participants were first welcomed by one of the bilingual researchers. She outlined the test components and objectives. Next, the consent form was signed and the demographics questionnaire completed using the cross-modal, bilingual, web-based questionnaire on a laptop computer. The participants sat in front of the eye-tracker at roughly $60 \mathrm{~cm}$ 
from the screen. After the standard 9-point calibration procedure, participants were asked to watch the clips. After each visualisation they answered both the linguistic and the visual memory questionnaires. The whole procedure carried out on each participant lasted about one hour.

\subsection{Results}

In order to analyse our data, we mainly used General Linear Models with repeated measures, that allowed us to compare the effect of different screen settings on Eye tracker recorded measures (Fixation Count, Fixation Duration Mean, Visit Count and Visit Duration Mean), on the Linguistic and Visual accuracy of recall (tested with questionnaires).

\subsubsection{ET measures}

\subsubsection{Effects of screen format and AOI on ET measures}

This analysis explores the effect of Format (format 1: SLI screen size 1/5; right, format 2: SLI screen size 1/5; left, format 3: SLI screen size 1/4; right, and format 4: SLI screen size 1/4; left) and Area: SLI area (AOI) and Scene screen area (Not AOI) on the above-mentioned ET measures. A summary of the data can be found in Table 2 .

\begin{tabular}{|l|c|c|c|c|c|c|c|c|}
\hline & $\begin{array}{c}\text { Fixation } \\
\text { Count } \\
\text { SLI }\end{array}$ & $\begin{array}{c}\text { Fixation } \\
\text { Count } \\
\text { Not AoI }\end{array}$ & $\begin{array}{c}\text { Fixation } \\
\text { Duration } \\
\text { Mean SLI }\end{array}$ & $\begin{array}{c}\text { Fixation } \\
\text { Duration } \\
\text { Mean } \\
\text { Not AoI }\end{array}$ & $\begin{array}{c}\text { Visit } \\
\text { Count } \\
\text { SLI }\end{array}$ & $\begin{array}{c}\text { Visit } \\
\text { Count } \\
\text { Not AoI }\end{array}$ & $\begin{array}{c}\text { Visit } \\
\text { Duration } \\
\text { Mean SLI }\end{array}$ & $\begin{array}{c}\text { Visit } \\
\text { Duration } \\
\text { Mean } \\
\text { Not AoI }\end{array}$ \\
\hline $\begin{array}{l}\text { Format 1 } \\
\text { Small/Right }\end{array}$ & 181,3 & 101,7 &, 56 &, 18 & 28,0 & 28,4 & 6,64 & 1,35 \\
\hline $\begin{array}{l}\text { Format 2 } \\
\text { Small/Left }\end{array}$ & 184,6 & 100,0 &, 43 &, 18 & 28,5 & 28,7 & 4,53 & 1,33 \\
\hline $\begin{array}{l}\text { Format 3 } \\
\text { Medium/ } \\
\text { Right }\end{array}$ & 164,1 & 107,8 &, 58 &, 19 & 27,8 & 28,0 & 4,95 & 4,01 \\
\hline $\begin{array}{l}\text { Format 4 } \\
\text { Medium/ } \\
\text { Left }\end{array}$ & 189,5 & 91,9 &, 46 &, 19 & 26,8 & 27,1 & 5,31 & 1,12 \\
\hline
\end{tabular}

Table 2: Mean values of ET measures for SLI screen and Scene screen (Not AOI) according to Format. 
The repeated measures analysis shows that the different formats do not have any effect on the measures Fixation Count $\left(\mathrm{F}_{(3,81)}=342, \mathrm{p}=.795\right.$; Partial Eta squared $=.12)$; Fixation Duration Mean $\left(\mathrm{F}_{(3,81)}=1.485, \mathrm{p}=.225\right.$; Partial Eta squared $=.52)$; Visit Count $\left(\mathrm{F}_{(3,81)}=.090, \mathrm{p}=.965 ;\right.$ Partial Eta squared $\left.=.003\right)$ nor on Visit Duration Mean $\left(\mathrm{F}_{(3,81)}=.674, \mathrm{p}=.570\right.$; Partial Eta squared $\left.=.024\right)$.

However, there are significant differences for all ET measures in the two areas (SLI screen /Scene screen): Fixation Count $\left(\mathrm{F}_{(1,27)}=23,231 ; \mathrm{p}=.000\right.$; Partial Eta Squared = . 462); Fixation Duration Mean $\left(\mathrm{F}_{(1,27)}=39,131 ; \mathrm{p}=.000\right.$; Partial Eta Squared = .592); Visit Count $\left(\mathrm{F}_{(1,27)}=18,875 ; \mathrm{p}=.000\right.$; Partial Eta Squared $=.411)$ and Visit Duration Mean $\left(\mathrm{F}_{(1,27)}=11,935 ; \mathrm{p}=.002\right.$; Partial Eta Squared $=.307)$. No interactions of Format and Area were found for any of the measures.

\subsubsection{Effects of size and AOI on ET measures}

As our findings did not show an effect on format, we decided to explore the two components of Format separately: Size of the SLI screen (Medium and Small) and Position of the SLI screen (Right or Left with respect to the Scene screen). A summary of this data can be found in Table 3 below.

\begin{tabular}{|c|c|c|c|c|c|c|c|c|c|}
\hline & & $\begin{array}{c}\text { Fixation } \\
\text { Count } \\
\text { SLI }\end{array}$ & $\begin{array}{c}\text { Fixation } \\
\text { Count } \\
\text { Not AoI }\end{array}$ & $\begin{array}{c}\text { Fixation } \\
\text { Duration } \\
\text { Mean } \\
\text { SLI }\end{array}$ & $\begin{array}{c}\text { Fixation } \\
\text { Duration } \\
\text { Mean } \\
\text { Not AoI }\end{array}$ & $\begin{array}{c}\text { Visit } \\
\text { Count } \\
\text { SLI }\end{array}$ & $\begin{array}{c}\text { Visit } \\
\text { Count } \\
\text { Not AoI }\end{array}$ & $\begin{array}{c}\text { Visit } \\
\text { Duration } \\
\text { Mean } \\
\text { SLI }\end{array}$ & $\begin{array}{c}\text { Visit } \\
\text { Duration } \\
\text { Mean } \\
\text { Not AoI }\end{array}$ \\
\hline Size & Small & 182,9 & 100,9 &, 49 &, 18 & 28,2 & 28,5 & 5,60 & 1,34 \\
\hline & Medium & 176,8 & 99,8 &, 52 &, 19 & 27,3 & 27,5 & 5,13 & 2,56 \\
\hline Position & Right & 173,0 & 104,7 &, 57 &, 19 & 27,9 & 28,2 & 5,83 & 2,63 \\
\hline & Left & 187,0 & 96,0 &, 44 &, 18 & 27,7 & 27,9 & 4,91 & 1,23 \\
\hline
\end{tabular}

Table 3: Mean values of ET measures for SLI screen and Scene screen (Not AoI) according to Size and Position.

The repeated measures analysis did not show any effect of SLI Size on the measures Fixation Count $\left(\mathrm{F}_{(1,29)}=.141 ; \mathrm{p}=.710 ;\right.$ Partial Eta Squared $\left.=.005\right)$; Fixation Duration Mean $\left(\mathrm{F}_{(1,29)}=.139 ; \mathrm{p}=.712\right.$;Partial Eta Squared $\left.=.005\right)$; Visit Count $\left(\mathrm{F}_{(1,29)}=.937 ; \mathrm{p}=.341 ;\right.$ Partial Eta Squared $\left.=.031\right)$ nor on Visit Duration Mean $\left(\mathrm{F}_{(3,81)}=.347, \mathrm{p}=.561 ;\right.$ Partial Eta squared $\left.=.012\right)$. 
The impact Area made was significant in all measures: Fixation Count: $\mathrm{F}_{(1,29)}=21.028 ; \mathrm{p}=.000$; Partial Eta Squared $=.420$; Fixation Duration Mean: $F_{(1,29)}=37.999 ; p=.000$; Partial Eta Squared $=.567$; Visit Count: $F_{(1,29)}=12.293$; $\mathrm{p}=.001$; Partial Eta Squared $=.353$; and Visit Duration Mean: $\mathrm{F}_{(1,29)}=15,833$; $\mathrm{p}=$,000; Partial Eta Squared $=, 298$. No interactions between Size and Area were found for any of these measures.

\subsubsection{Effects of position and area of interest on ET measures}

The analysis of the effect of Position of the SLI screen regarding the Scene screen did not show any significant differences in ET measures: Fixation Count: $F_{(1,31)}=.006 ; p=.931$, Partial Eta Squared $=.000$; Fixation Duration Mean: $F_{(1,31)}=3.262 ; p=.081$, Partial Eta Squared $=.095$; Visit Count: $F_{(1,31)}=$ $.002 ; \mathrm{p}=.961$, Partial Eta Squared $=.353$; and Visit Duration Mean: $\mathrm{F}_{(1,31)}=$ $2.266 ; \mathrm{p}=.142$; Partial Eta Squared $=.068$. Area had a clear effect on all measures: Fixation Count: $F_{(1,31)}=22.984 ; p=.000$, Partial Eta Squared $=.426$; Fixation Duration Mean: $F_{(1,31)}=37.137 ; p=.000$, Partial Eta Squared $=.545$; Visit Count: $\mathrm{F}_{(1,31)}=19.821 ; \mathrm{p}=.000$, Partial Eta Squared $=.390$; and Visit Duration Mean: $\mathrm{F}_{(1,31)}=14.477 ; \mathrm{p}=.001$; Partial Eta Squared $=.318$. No interactions between Position and Area were found for any of these measures.

\subsubsection{Dominant hand and Position effects within the SLI screen on ET measures}

In order to examine visual attention given to the dominant hand on the visual exploration of the screen, we split the SLI screen into ipsilateral (the dominant hand side) and contralateral (the non-dominant hand) areas and compared the ET measures obtained for both sides in relation to the position of the SLI screen with respect to the Scene screen.

The repeated measures analysis did not show significant differences for Fixation Count according to Position $\left(\mathrm{F}_{(1,30)}=.174 ; \mathrm{p}=.680\right.$; Partial Eta Squared $=.006)$ nor Dominant Hand side $\left(\mathrm{F}_{(1,30)}=.544 ; \mathrm{p}=.467\right.$; Partial Eta Squared $=.018)$. No interaction can be reported either.

Similar results are obtained for Fixation Duration Mean, according to Position $\left(\mathrm{F}_{(1,30)}=.084 ; \mathrm{p}=.774\right.$; Partial Eta Squared $\left.=.003\right)$ and Dominant 
Hand side $\left(\mathrm{F}_{(1,30)}=, 337 ; \mathrm{p}=, 566 ;\right.$ Partial Eta Squared= ,011). No interaction was found either.

However, the analysis of the differences in Visit Count did show the statistical significance of Position $\left(F_{(1,30)}=4.375 ; \mathrm{p}=.45\right.$; Partial Eta Squared $\left.=.127\right)$. No effects were found concerning the Dominant/Non-dominant Hand side $\left(\mathrm{F}_{(1,30)}=.009 ; \mathrm{p}=.924 ;\right.$ Partial Eta Squared $\left.=.000\right)$, but there was a significant interaction between Position and Hand Side $\left(F_{(1,30)}=4.710 ; p=.038\right.$; Partial Eta Squared $=.136)$. The Dominant hand side received more visits when it was placed at the Right of the Scene screen, while the contrary was found for the Non-dominant hand side. This interaction is depicted in Figure 6.

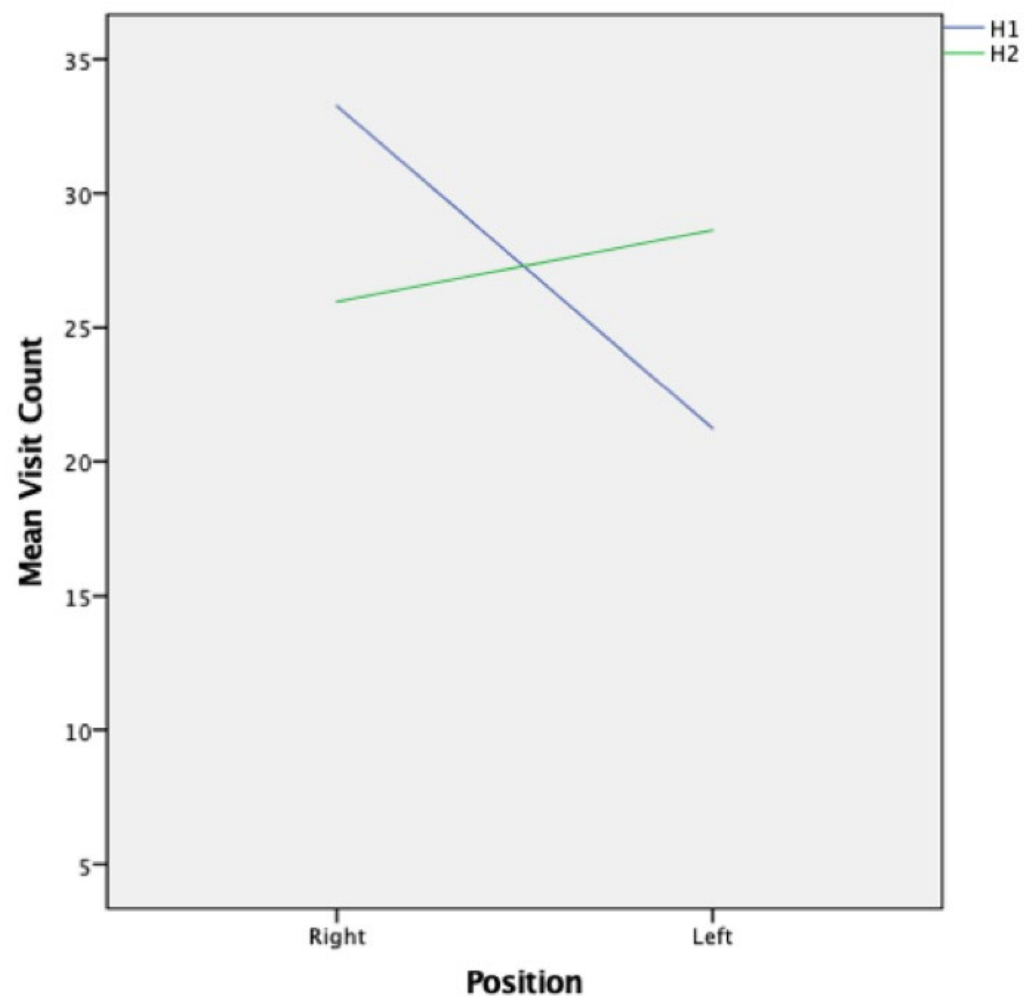

Figure 6. Interaction between position of the SLI and visits received by each hand-side. 
No effects were found for the Visit Duration mean measure, nor for Position $\left(\mathrm{F}_{(1,30)}=1.345, \mathrm{p}=.255\right.$; Partial Eta Squared $\left.=.043\right)$, nor Hand $\left(\mathrm{F}_{(1,30)}=1.558\right.$; $\mathrm{p}=.222$; Partial Eta Squared $=.049$.

\subsubsection{Effects of format on language and scene recall results}

A General Linear Model with repeated measures was carried again to test the effects of the screen format on the scores obtained in both recall questionnaires. Values can be seen on Table 4.

We did not find effects of Format on Recall: $\mathrm{F}_{(3,84)}=1.921 ; \mathrm{p}=.132$; Partial Eta Squared $=.064$, but we did find significant effects of type of recall: $F_{(1,28)}=$ 10,$783 ; \mathrm{p}=.003 ;$ Partial Eta Squared= .278.

\begin{tabular}{|l|c|c|c|c|c|c|c|c|c|c|c|c|}
\hline \multicolumn{1}{|c|}{ Format } & \multicolumn{2}{|c|}{ f1: Small/right } & \multicolumn{3}{c|}{ f2 small/left } & \multicolumn{3}{c|}{ f3 medium/right } & \multicolumn{3}{c|}{ f4 medium/left } \\
\hline & Mean & St Dev & Valid N & Mean & St Dev & Valid N & Mean & St Dev & Valid N & Mean & St Dev & Valid N \\
\hline $\begin{array}{l}\text { Language } \\
\text { Recall }\end{array}$ & 2.19 & 1.45 & 31 & 2.60 & 1.10 & 30 & 2.45 & 1.36 & 31 & 2.34 & 1.15 & 32 \\
\hline Scene Recall & 1.52 & 1.06 & 31 & 1.73 & 1.28 & 30 & 1.94 & 1.21 & 31 & 2.34 & 1.18 & 32 \\
\hline
\end{tabular}

Table 4. Mean scores obtained for the scene recall and language recall according to the different screen formats.

Since scene recall and language recall are different, according to the repeated measures analysis, we carried out planned comparisons between both scores in each format. The results point out that mean scores for the scene recall and the language recall are significantly different for $\mathrm{fl}\left(\mathrm{t}_{(30)}=2.358 ; \mathrm{p}=.025\right)$ and for $\mathrm{f} 2\left(\mathrm{t}_{(29)}=3.432 ; \mathrm{p}=.002\right)$, in which language recall is better than scene recall. For the scene recall in format $\mathrm{f} 3$ and $\mathrm{f} 4$, however, differences are not significant $\left(\mathrm{f} 3: \mathrm{t}_{(30)}=1.609 ; \mathrm{p}=.118 ; \mathrm{f} 4: \mathrm{t}_{(31)}=.000 ; \mathrm{p}=1\right)$.

We also carried planned comparisons within each type of test to compare the results obtained for each format. T-tests show significant differences between Scene recall scores obtained with Format 1 and Format $4\left(t_{(30)}=3,233\right.$; $\mathrm{p}=.003)$ and a trend of significance between Format 3 and Format $4\left(\mathrm{t}_{(30)}=\right.$ 1.995; $\mathrm{p}=.055$ ). That is, Format 4 (medium/left) produces significantly better results of the scene recall than Format 1 (small/right) and Format 3 (medium/ right). No significant differences were found for Language recall across formats. 


\section{Discussion}

Even though sign language access services on TV target hours have not yet been met, SLI service broadcast hours have been growing over the past few years. The goal of our study, under the scope of the HBB4ALL project, was to provide experiments to support recommendations for broadcasters regarding size and position of the SLI on screen.

In this reception study we researched the user's visual behaviour and information processing of sign-interpreted TV access service while watching video clips in different split screen configurations. We recorded participants' eye movements and scored their performance on memory questionnaires about the language and scene content. Our purpose was to explore if different split screen formats elicited differences in the way information content on screen is processed. Although our experimental reception study is largely exploratory we found some interesting findings that we discuss later.

We also carried planned comparisons within each type of test to compare the results obtained for each format. T-tests show significant differences between Scene recall scores obtained with Format 1 and Format $4\left(\mathrm{t}_{(30)}=\right.$ 3,$233 ; \mathrm{p}=.003$ ) and a trend of significance between Format 3 and Format 4 $\left(\mathrm{t}_{(30)}=1.995 ; \mathrm{p}=.055\right)$. That is, Format 4 (medium/left) produces significantly better results for the scene recall than Format 1 (small/right) and Format 3 (medium/right).

Turning first to the ET data, regarding screen exploration in the four different formats, we found that sign language users spent a longer time watching the LS screen than the scene screen, independently of the split screen format, the screen size or the SLI and the side of display. These results on attention distribution among the different splits screens on the TV are consistent with Wehrmeyer's findings (2014) with news broadcasts. The repeated measures analysis showed that the different formats, size and position conditions do not have any effect on the ET measures. Likewise, no interactions were found for any of the ET measures. We hypothesise that this consistency among the different split screen variables and conditions might be related to the nature of the content and also the task in our experiment, which was one of the controlled variables in our clip design. In all the documentary video clips, scene content and language content were relevant to task completion and designed to be balanced among the different conditions. 


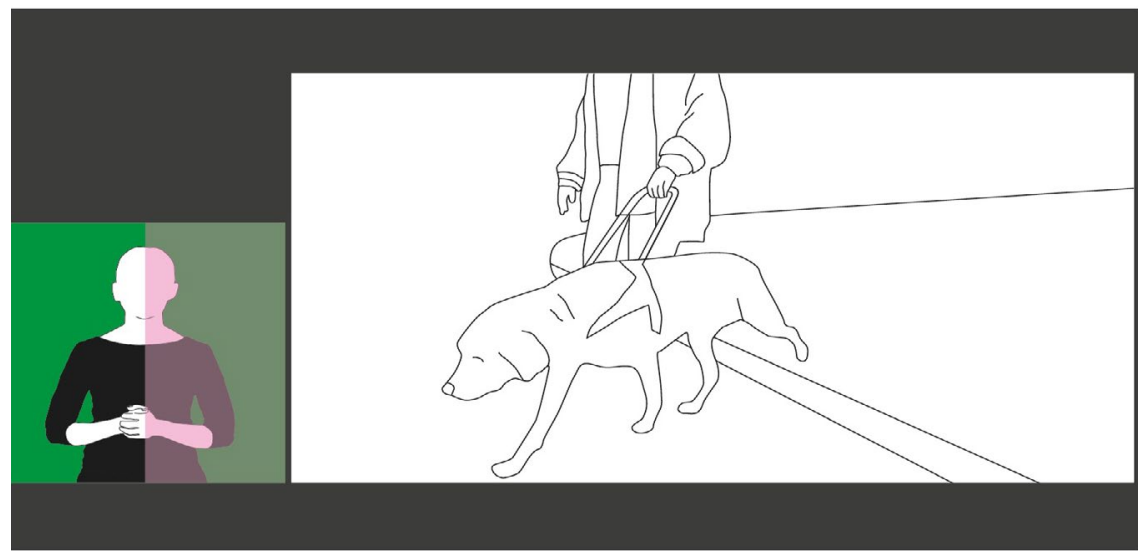

Figure 7. Proximal contralateral side (shaded in pink) in format 4

With regard to the visual exploration of ipsilateral $(\mathrm{H} 1)$ and contralateral (H2) sides of the SLI area, the results show a difference between attention distribution in the two position conditions, as predicted. However, our directional hypothesis is not confirmed: the number and duration of fixations and visits is not higher for Hl SLI area in any position conditions. Although the number of visits for $\mathrm{H} 1$ and $\mathrm{H} 2$ areas is the same, there is an interaction between right/left positions and dominance side in the number of visits (see Figure 6). Namely, the visit count is higher on the ipsilateral side (H1) of the SLI area in the right positions, whereas it is higher on the contralateral side (H2) of the SLI area for the left positions. Therefore, our results suggest that deaf participants tend to focus their attention on the side of the SLI screen that is more proximal to the scene screen, regardless of the hand dominance. The shaded area in Figure 7 illustrates the proximal part of the SLI screen in format 4 which is the part receiving most focused attention, in left positions this side corresponds to the contralateral side of the interpreter. We hypothesise that by focusing their attention on the proximal part of the SLI screen to the scene screen, participants can include more information content within their peripheral visual field. The heat maps below in Figures 8 - 11 illustrate the different foci of attention for the right/left conditions in the four split screen formats. 


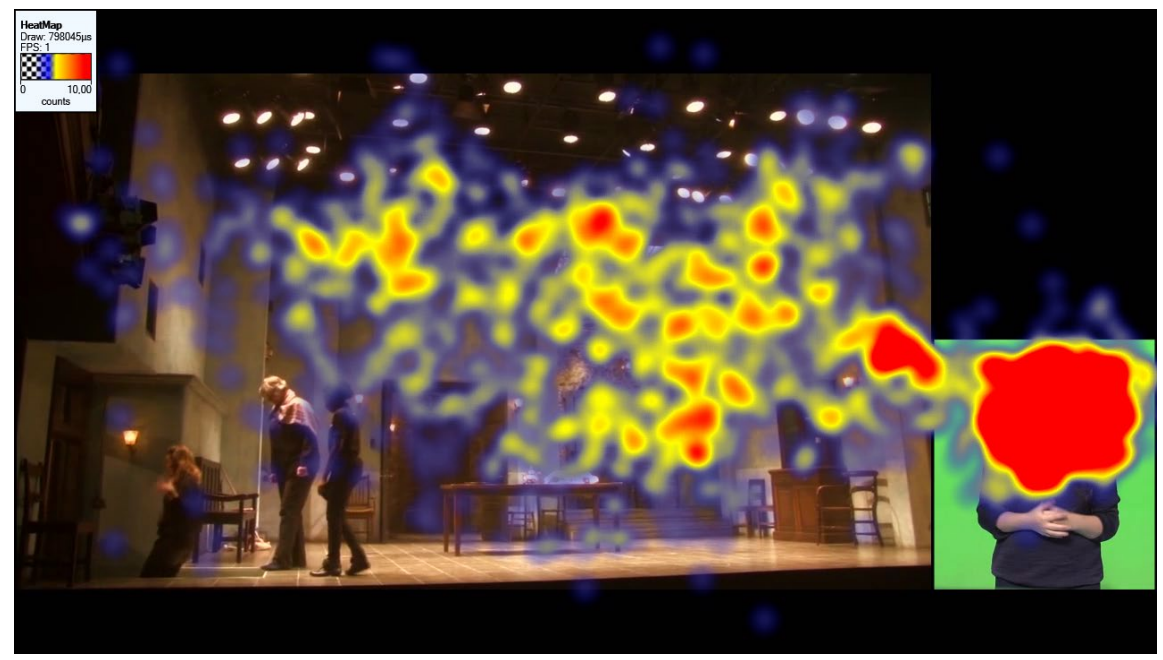

Figure 8. Format 1 gaze pattern heat map for all participants in clip 3

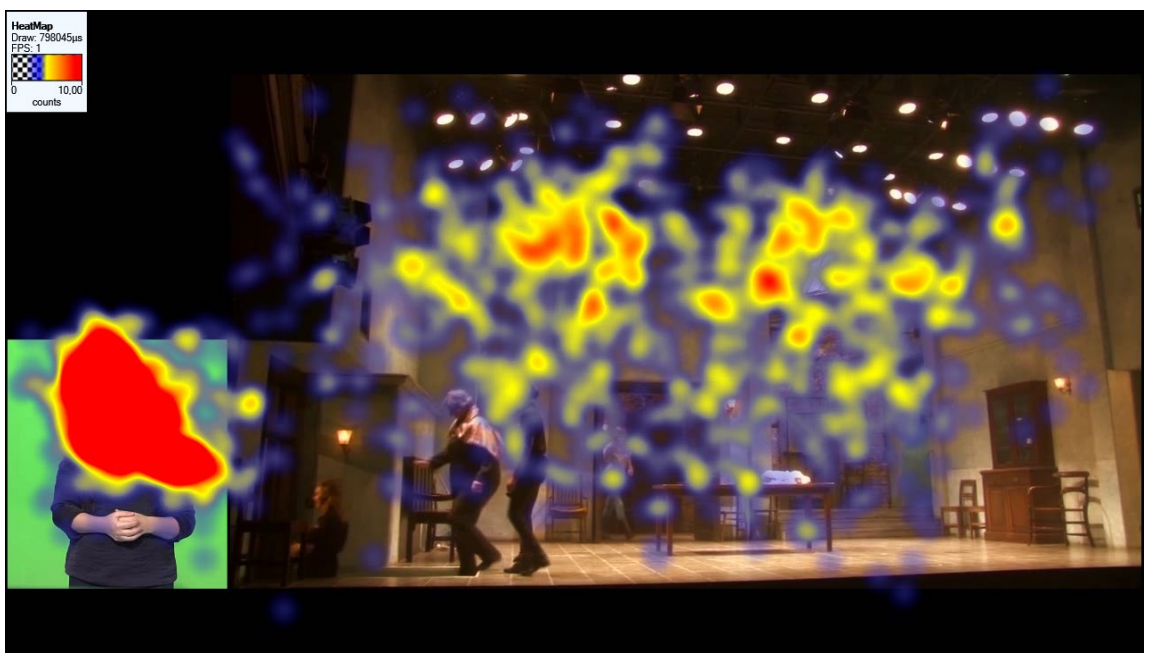

Figure 9. Format 2 gaze pattern heat map for all participants in clip 3 


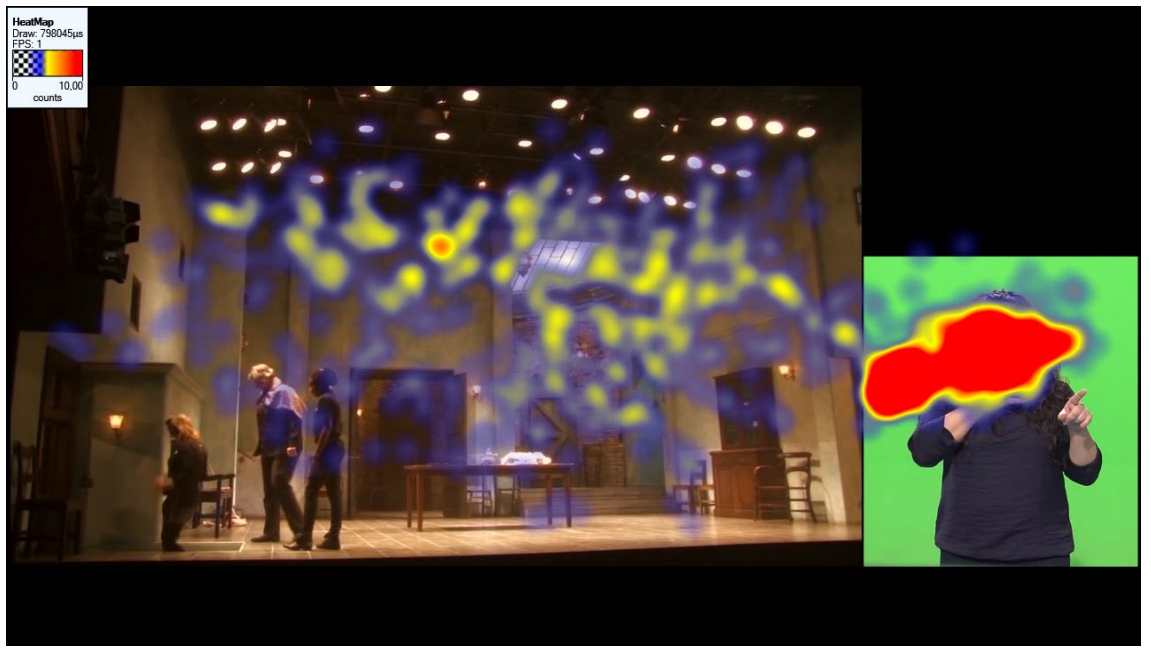

Figure 10. Format 3 gaze pattern heat map for all participants in clip 3

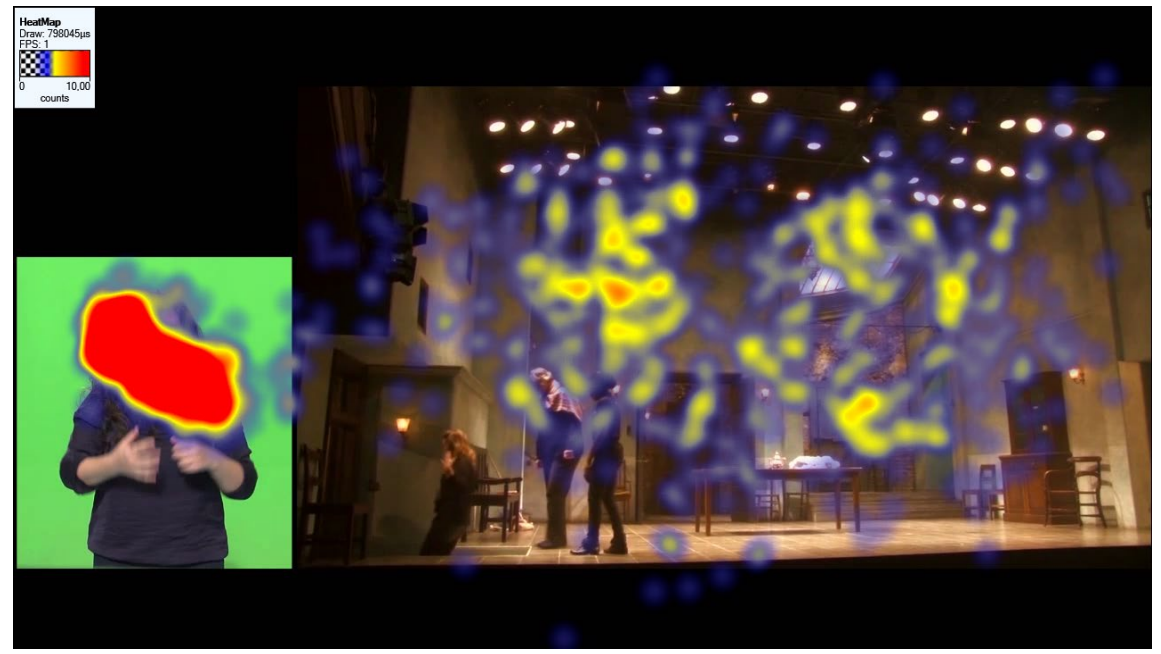

Figure 11. Format 4 gaze pattern heat map for all participants in clip 3 
Regarding the recall test results, our findings show that the responses to the language recall tests are significantly more accurate than those of the scene recall tests when the SLI appears in small formats, formats 1 and 2. However, when the SLI screen size is medium, in formats 3 and 4, the differences in scores between language and scene recall are not significant. We assume that this contrast is associated with the size of the SLI screen. Although the focus of attention is not evenly distributed between the two split screens, according to ET metrics, the bigger size of the SLI screen probably allows for visual attention to absorb the scene details, using the peripheral, visual perception mentioned above.

Concerning the interaction between the recall scores and the four format combinations, the results indicate that format is not significantly related to language recall performance. However, there are differences regarding scene recall scores, which are the highest in format 4 , the format combining the medium sized SLI screen in the left position, and the lowest in format 1 , combing a small sized SLI in the right position. Specifically, the data analysis indicates differences between format 4 and both of the other formats, including the SLI screen on the right position. The results show a significant difference between format 4 and format 1 , and a trend of significance between format 4 and format 3 .

These recall results suggest that the format including an SLI medium screen on the left is a good split screen configuration that facilitates information recall from the scene screen. It is also the format with more balanced mean scores between the language and scene recall tests. This finding suggests that right visual field enhancement, or left-hemisphere bias (Bavelier et al. 2001), could also have an effect on complex visual information processing, such as watching interpreted TV content on a split screen configuration. However, this finding might also be showing effects of a bias in participant sample. As our participants are all Catalan sign language users they might be showing a learning effect, as the medium-size left-position SLI screen is the format used in the daily news of the Catalan public broadcaster. Even though this finding is internally valid for our research, more research is needed to grant the external validity of the results. 


\section{Final remarks}

This experimental reception study has shown how deaf sign language users explore a sign-interpreted documentary on TV using a split screen configuration. Although mostly exploratory in nature, the findings suggest that the format used to deploy the service impacts the accessibility of information contents, both textual and non-textual. The differences found in accuracy recall of the documentary content have been associated with format conditions, size and on-screen positioning.

Our findings suggest that including a SLI of medium size ( $1 / 4$ of the TV screen width) in a left position can contribute to better content access for deaf sign language users. The results indicate that this screen configuration encompasses the optimal formal parameters, enhancing screen legibility and balancing comprehension to both language and scene content. Broadcasters deploying SLI services should consider that the formal parameters choices do not only affect aesthetics but have an impact on content accessibility.

As the application of eye tracking methods in SLI access services is still fairly unexplored, future studies should endeavor to research other formal parameters that may affect sign language processing, such as the use of Chroma key or background colour, which may also impact on perception and usability of the service. These factors might be crucial to improve media experience not only for all members of the sign language communities, but especially for those with a combined sensory loss such as deafblind sign language users or the elderly.

More research is needed not only in order to study the formal parameters, but also for different national sign languages, age groups, TV genres, signing models and newer devices, in order to improve the quality of this access service with a view to offering real personalisation options. We believe that to guarantee equal rights in information accessibility and participation in society for sign language communities, it is of the utmost importance to strive for quantity and quality in media access services in sign language. 


\section{References}

AGRAFiotis, Dimitris; Nishan Canagarajah; David R. Bull \& Matthew Dye. (2003) "Perceptually optimised sign language video coding based on eye tracking analysis." Electronics Letters 39:24, pp. 1703-1705. Electronic version: <http:// doi.org/10.1049/el:20031140>

Allsop, Lorna \& Jim Kyle. (2008) "Translating the news. A deaf translator's experience." In: Kellett, Cynthia \& Eleana Ochse (eds.) 2008. English in international deaf communication. Bern: Peter Lang, pp. 383-400.

Bavelier, Daphne; Craig Brozinsky; Andrea Tomann; Teresa Mitchell, Helen Neville \& Guoying Liu. (2001) "Impact of Early Deafness and Early Exposure to Sign Language on the Cerebral Organization for Motion Processing." The Journal of Neuroscience 21:22, pp. 8931-8942.

BosCH-BAliardA, Marta; Olga Soler-Vilageliu \& Pilar Orero. (2019) "Toward a Sign Language-Friendly Questionnaire Design." Journal of Deaf Studies and Deaf Education (accepted for publication). Electronic version: <http://doi. org/deafed/enz021>

Bosch-BAliardA, Marta; Olga Soler-Vilageliu \& Pilar Orero. (in prep.) "Toward recommendations for TV sign language interpretation formal parameters." Journal of Audiovisual Translation (accepted for publication).

DE MeUlder, Maartje \& Isabelle Heyerick. (2013) "(Deaf) Interpreters on Television: Challenging Power and Responsibility." In: Meurant, Laurence; Aurélie Sinte; Mieke Van Herreweghe \& Myriam Vermeerbergen (eds.) 2013. Sign Language Research, Uses and Practices. Crossing Views on theoretical and applied sign language linguistics. Berlin: De Gruyter Mouton, pp. 111-136.

DunCAN, Bob. (1997) "Deaf people interpreting on television." Deaf Worlds, International Journal of Deaf Studies 13:3, pp. 35-39.

DyE, Matthew W. G.; Peter C. Hauser \& Daphne Bavelier. (2009) "Is Visual Selective Attention in Deaf Individuals Enhanced or Deficient? The Case of the Useful Field of View." PLoS ONE 4:5, e5640. Online version: <http://doi. org/10.1371/journal.pone.0005640>

DYE, Matthew W. G., Jenessa L. Seymour \& Peter C. Hauser. (2016) "Response bias reveals enhanced attention to inferior visual field in signers of American Sign Language." Experimental Brain Research 234, pp. 1067-1076. Electronic version: <http://doi.org/10.1007/s00221-015-4530-3>

GEERTS, David; Pablo Cesar \& Dick Bulterman. (2008) "The implications of program genres for the design of social television systems." In: UXTV '08 
Proceedings of the 1st international conference on Designing interactive user experiences for TV and video, pp. 71-80.

GiL-SABROSO, Esther \& Francisco Utray. (2016) "Sign language in Spanish television. Study on reception." Área Abierta 16, pp. 17-37. Electronic version: <http://dx.doi.org/10.5209/rev_ARAB.2016.v16.n1.47508>

GRBIĆ, Nadja. (2002) "Kein Fall für Notfälle. Gebärdensprachdolmetschen." In: Kurz, Ingrid \& Angela Moisl (eds.) 2002. Berufsbilder für Übersetzer und Dolmetscher. Perspektiven nach dem Studium. Wien: WUV-Universitätsverlag, pp. 181-189.

KRAUSNEKER, Verena. (2008) The protection and promotion of sign languages and the rights of their users in Council of Europe member states: needs analysis. Strasbourg: Council of Europe. Electronic version: <https://www.ecml.at/ Portals/1/documents/CoE-documents/The_protection_and_promotion_sign_ language_eng.pdf.pdf>

KURZ, Ingrid \& Brigitta Mikulasek. (2004) "Television as a Source of Information for the Deaf and Hearing Impaired. Captions and Sign Language on Austrian TV." Meta 49:1, pp. 81-88. doi:10.7202/009023ar

KyLE, Jim. (2007) Sign on Television: Analysis of Data. Bristol: Deaf Studies Trust. Electronic version: <http://stakeholers.ofcom. org.uk/binaries/consultations/ signing/responses/deafstudies_annex.pdf>

LADD, Paddy. (2003). Understanding deaf culture. Clevedon: Multilingual Matters.

Letourneau, Susan M. \& Teresa V. Mitchell. (2011) "Gaze patterns during identity and emotion judgments in hearing adults and deaf users of American Sign Language." Perception 40:5, pp. 563-575. Electronic version: <https:// doi.org/10.1068/p6858>

Looms, Peter Olaf. (2009) "E-inclusiveness and digital television in Europe - a holistic model." In: Stephanidis, Constantine (ed.) 2009. Universal Access in Human-Computer Interaction. Addressing Diversity. Berlin: Springer Verlag, pp. 550-558.

MÄKIPÄÄ, A. \& A. Hämesalo. (1993) Towards Full Participation and Equal Rights. Helsinki: World Federation of the Deaf.

Martín Edo, Carlos Alberto; Pilar Orero; José Manuel Menéndez García \& Guillermo Cisneros Pérez. (2015) "Signing provision in connected TV: HBB4ALL project." IEEE International Symposium on Broadband Multimedia Systems and Broadcasting, pp. 1-5. Electronic version: <https://doi.org/10.1109/ BMSB.2015.7177264> 
MAS, Lluís \& Pilar Orero. (2018) "New Subtitling Possibilities: Testing Subtitle Usability in HbbTV." Translation Spaces 7:2, pp. 263-284.

Nebel, Katarina; Holger Weise; Phillip Stude; Armin De Greiff; Hans-Christoph Diener \& Matthias Keidel. (2005) "On the neural basis of focused and divided attention." Cognitive Brain Research 25, pp. 760-776.

ORERO, Pilar; Javier Serrano; Olga Soler; Anna Matamala; Judit Castellà; Maria Teresa Soto Sanfiel; Anna Vilaró; Carme Mangiron. (2014) "Accessibillity to Digital Society: Interaction for All." Think Mind, pp. 188-191. Electronic version: <http://www.thinkmind.org/index. php?view=article\&articleid=icds_2014_8_10_10031>

Oliver Moreno, Andreu. (2017) Attention and Dual Coding Theory: an Interaction Model Using Subtitles as a Paradigm. Bellaterra: Universtitat Autònoma de Barcelona. Tesis doctoral.

PARASNIS, Ila \& Vincent J. Samar. (1985) "Parafoveal attention in congenitally deaf and hearing young adults." Brain Cogn 4:3, pp. 13-327.

Redón SAla, Núria. (2014) Qualitat en la interpretació de llengua de signes a la televisió: accessibilitat a la cultura. Barcelona: Universitat Autònoma de Barcelona. Trabajo Final de Grado en Logopedia.

SANDLER, Wendy. (2013) "The phonological organization of sign languages." Language and Linguistics Compass 6:3, pp. 162-182.

SeleskovitCH, Danica. (1997) "Interview de Mme Arlette Morel, présidente de la Féderation nationale des sourds de France." META 42:3, pp. 560-563.

SIPLE, Patricia. (1978) "Visual constraints for sign language communication." Sign Language Studies 19, pp. 95-110.

SOleR Vilageliu, Olga; Marta Bosch-Baliarda \& Pilar Orero. (2015) "Hbb4All: Diseño de experimentos con usuarios para evaluar la recepción de LSE en TV." Congreso CNLSE de la Lengua de Signos Española 2015. Electronic version: <https://www.youtube.com/watch? $\mathrm{v}=$ WMVEAauAAPk>

STEINER, Ben. (1998) "Signs from the Void: The Comprehension and Production of Sign Language on Television." Interpreting 3:2, pp. 99-146.

STONE, Christopher. (2007) "Deaf access for deaf people: the translation of the television news from English into British sign language." In: Díaz Cintas, Jorge; Pilar Orero \& Aline Remael (eds.) 2007. Media for all: subtitling for the deaf, audio description and sign language. Amsterdam: Rodopi, pp.71-88. Electronic version: <http://discovery.ucl.ac.uk/123190/1/123190_Transmedia07.pdf> 
STONE, Christopher \& Donna West. (2012) "Translation, representation and the Deaf 'voice'." Qualitative Research 12, pp. 645-665.

UTRAY, Francisco \& Esther Gil Sabroso. (2014) "Diversidad cultural, lengua de signos y televisión en España." Fonseca Journal of Communication 9, pp. 118-143. Electronic version: <http://revistas.usal.es/index.php/2172-9077/ article/view/12244/12597>

WEHRMEYER, Jennifer. (2014) "Eye-tracking Deaf and hearing viewing of sign language interpreted news broadcasts." Journal of Eye Movement Research 7(1):3, pp. 1-16

XIAO, Xiaoyan \& Freyan Li. (2013) "Sign language interpreting on Chinese TV: a survey on user perspectives." Perspectives 21:1, pp. 100-116. Electronic version: <https://doi.org/10.1080/0907676X.2011.632690>

SeVeral Authors (Centro de Normalización Lingüística de la Lengua de Signos Española, CNLSE). (2015) Informe. Presencia de la lengua de signos española en la televisión. Madrid: Real Patronato sobre Discapacidad.

SeVeral Authors (Centro de Normalización Lingüística de la Lengua de Signos Española, CNLSE). (2017) Guía de buenas prácticas para la incorporación de la lengua de signos española en televisión. Madrid: Real Patronato sobre Discapacidad.

SeVeral Authors (DTV4ALL). (2008) Digital Television for All. Electronic version: <http://www.psp-dtv4all.org>

SeVEral Authors (European Broadcasting Union, EBU). (2016) "Access Services Pan European Survey." Electronic version: <https://www.ebu.ch/files/live/ sites/ebu/files/Publications/Presentations/EBU\%20Access\%20Services\%20 Survey\%202016.pdf>

SeVeral Authors (European Comission). (2010) European Disability Strategy 2010-2020: A Renewed Commitment to a Barrier-Free Europe. Brussels: European Comission. Electronic version: <https://eurlex.europa.eu/ LexUriServ/LexUriServ.do?uri=COM:2010:0636:FIN:en:PDF>

SEVeral Authors (European Parliament). (2010) Directive 2010/13/EU of the European Parliament and of the Council of 10 March 2010 on the coordination of certain provisions laid down by law, regulation or administrative action in Member States concerning the provision of audiovisual media services (Audiovisual Media Services Directive). Strasbourg: European Parliament and Council of the European Union. Electronic version: <https://eur-lex.europa. eu/legal-content/EN/ALL/?uri=CELEX:32010L0013> 
SEVEral Authors (European Parliament). (2015) Proposal for a DIRECTIVE OF THE EUROPEAN PARLIAMENT AND OF THE COUNCIL on the approximation of the laws, regulations and administrative provisions of the Member States as regards the accessibility requirements for products and services. Brussels: European Commission. Electronic version: <https://eur-lex.europa.eu/ legal-content/EN/TXT/?uri=COM:2015:0615:FIN>

SeVERAl Authors (European Regulators Group for Audiovisual Media Services, ERGA). (2016) Special task report on the provision of greater accessibility to audiovisual media services for persons with disabilities. Electronic version: <ec. europa.eu/newsroom/document.cfm?doc_id=40610>

SEVEral Authors (European Union of the Deaf, EUD). (2019) "European Disability Strategy Survey." Electronic version: <https://www.eud.eu/ test-survey/>

SeVeral Authors (HBB4ALL). (2017) "HBB4ALL Deliverables." Electronic version: <http://pagines.uab.cat/hbb4all/content/deliverables>

Several Authors (Independent Television Commission). (2010) Guidelines on Standards for Sign Language on Digital Terrestrial Television. In Codes \& Guidance Notes (Subtitling, Signing \& Audio Description). Electronic version: <http://webarchive.nationalarchives.gov.uk/20100109083629 http://www. ofcom.org.uk/static/archive/itc/itc_publications/codes_guidance/sign_language_dtt/index.asp.html>

SEVERAL Authors (National Deaf Children's Society, NDCS). (2005) In their own words: Young deaf people's access to television. London: The National Deaf Children's Society.

Several Authors (National Disability Authority, NDA). (2014) "Guidelines for Digital TV equipment and services." In: Irish National IT Accessibility Guidelines (Sign Language Interpreting). Electronic version: <http://universaldesign. ie/Technology-ICT/Irish-National-IT-Accessibility-Guidelines/Digital-TVequipment-and-services/guidelines-for-digital-tv-equipment-and-services/ Sign-Language-Interpreting/>

SEVERAl Authors (Office of Communications, Ofcom). (2007) Signing on television. New arrangements for low audience channels. Electronic version: <https:// www.ofcom.org.uk/_data/assets/pdf_file/0015/41433/statement.pdf>

SeVeral Authors (Spanish Parliament). (2010) Ley General de la Comunicación Audiovisual. Electronic version: <https://www.boe.es/buscar/pdf/2010/BOEA-2010-5292-consolidado.pdf> 


\section{BIONOTES / BIONOTAS}

MARTA BOSCH BALIARDA is a sign language linguist and interpreter specialised in Deaf studies who has worked as a trainer for sign language interpreters, sign language teachers and communication support workers. She is currently a PhD research assistant in the research group TransMedia Catalonia from the Autonomous University of Barcelona and working on sign language accessibility services.

MARTA BOSCH BALIARDA és lingüista i intèrpret de llengua de signes especialitzada en estudis de persones sordes. Ha treballat com a formadora d'intèrprets de llengua de signes, professors de llengua de signes i treballadors de suport a la comunicació. Actualment és assistent d'investigació de doctorat al grup de recerca TransMedia Catalonia de la Universitat Autònoma de Barcelona i treballa en serveis d'accessibilitat en llengua de signes.

Olga SOlER VILAGELIU is an associate professor at UAB, where she teaches psycholinguistics and cognitive processing to undergraduates in Psychology and Speech Therapy. With a background in language processing, her research has focused on on-line measuring of handwriting in preschool and school children. Within the TransMedia projects she is currently setting up experiments on different accessibility services: quality of perception of Sign Language on TV and emotional involvement of users of Audio description and Audio Subtitling.

Olga SOLER VILAGELIU és professora associada de la UAB, on imparteix classes de psicolingüística i processament cognitiu a estudiants de grau de Psicologia i Logopèdia. Amb experiència en el processament del llenguatge, la seva recerca s'ha centrat en el mesurament en línia de l'escriptura a mà en nens en edat preescolar i escolar. En el marc dels projectes de TransMedia, actualment està preparant experiments sobre diferents serveis d'accessibilitat: qualitat de percepció de la llengua de signes a la televisió i implicació emocional dels usuaris d'audiodescripció i d'àudio-subtítols.

PILAR ORERO is an associated professor at the Faculty of Translation at Universitat Autònoma de Barcelona. She works in the field of Media Accessibility She has edited 12 books and wrote 86 papers in international journals, and more than 40 book chapters. Leader of numerous research projects funded by the 
Spanish and Catalan Gov. She leads TransMedia Catalonia Group (20052017) and the Audio Description and Audio Subtitling group at UN agency ITU 2011-2013 focus group on Media Accessibility. She is now working for WSIS+10. Co-editor of ISO/IEC JTC 1/SC 35 N on Audio Description.

Pilar Orero és professora associada a la Facultat de Traducció de la Universitat Autònoma de Barcelona. Treballa en l'àmbit de l'accessibilitat als mitjans de comunicació. En els darrers deu anys ha editat 12 llibres i escrit 86 publicacions en revistes internacionals i més de 40 capítols de llibres. Líder de nombrosos projectes d'investigació finançats pel governador espanyol i català. Dirigí TransMedia Catalonia Group (2005-2017) i el grup Audio Description i Audio Subtitling dins el grup de debat sobre l'accessibilitat als mitjans de comunicació de l'ONU ITU 2011-2013. Ara treballa per a WSIS + 10. Coeditor de ISO / IEC JTC 1/ SC 35 N en Descripció d'àudio. 